\title{
Prosthetic Mesh Use for Esophageal Hiatal Hernia Repair
}

\author{
Wen-Ping Wang, Yu-Shang Yang, Qi-Xin Shang, and Long-Qi Chen* \\ Department of Thoracic Surgery, West China Hospital, Sichuan University, Chengdu 610041, China
}

Received: May 08, 2018; Published: May 17, 2018

*Corresponding author: Long-Qi Chen, Department of Thoracic Surgery, West China Hospital, Sichuan UniversityNo37, Guoxue Alley, Chengdu, Sichuan 610041, China

Abbreviations: EHH: Esophageal Hiatal Hernia; PTFE: Polytetrafluoroethylene; HADM: Human Acellular Dermal Matrix Patch; PSIS: Porcine Small Intestinal Submucosal; TCPP: Titanium-Coated Polypropylene

\section{Introduction}

Massive hiatal hernia (type II, III and IV), mostly presenting obvious symptoms and leading to severe complications, was necessarily recommended to be treated by surgical procedure timely. The principles of surgical procedures included reduction of the stomach into the abdomen, sac excision, crural closure, and gastropexy or fundoplication [1,2]. Laparoscopic procedure has been commonly applied for the EHH repair [3]. Luketich's largescale (662 patients) postoperative outcome after EHH repair showed that rate of hernia recurrence verified by radiography was $15.7 \%$, and rate of reoperation due to recurrence was $3.17 \%$ [4]. Measurements to reduce the recurrence rate after $\mathrm{PEH}$ repair should focus on minimizing tension and crural relaxing incisions when necessary. The use of mesh likely is another option that will improve outcomes after EHH repair [5]. High recurrence following laparoscopic repair led to more popularity of mesh use in order to decrease the high postoperative recurrence. A questionnaire on mesh utilization from the members of the Society of Gastrointestinal and Endoscopic Surgeons showed that the most common indication for mesh usage was an increased size of hiatal defect [6].

\section{Utilization of Prosthetic Mesh for Esophageal Hiatal Hernia Repair}

I. Commonly Used Mesh Types for EHH Repair Included: Polytetrafluoroethylene (PTFE), human acellular dermal matrix (HADM), porcine small intestinal submucosal (PSIS), and titanium-coated polypropylene (TCPP), but no one mesh type was clearly superior in terms of avoiding failure and complication[7]. It is considerably necessary to use the mesh reinforcement for large defect or fragile closure[8]. The ideal mesh is considered being easy to handle during laparoscopy, able to adhere to the diaphragmatic surface, and benign to the visceral surface on the other side [9]. Use of prosthetic mesh reinforcement of cruroplasty in large hiatal hernias could effectively prevent hernia recurrences, although the operation time was commonly longer in the mesh group[10]. Furnee's meta-analysis showed that there was no or only a small recurrence in 385 patients in the mesh group and in 182 of 247 (73.7 \%) in the non-mesh group [11]. As well Huddy's meta-analysis presented that mesh significantly reduced overall recurrence rates compared to simple suture (14.5 vs. $24.5 \%, \mathrm{P}=0.009$ ) [12]. Oelschlager and colleagues reported the outcomes of a multicenter randomized controlled trial that compared the use of biological mesh during laparoscopic EHH repair, with conventional primary cruroplasty. A significant lower recurrence rate at 6 months after surgery was found in the mesh group than the group of patients who underwent cruroplasty alone (9\% vs. $23 \%, \mathrm{P}<0.05)$ [13].

\section{Mesh-Associated Long-Term Complication}

Safety of mesh several reports concerning mesh-associated severe complications appeared along with mesh spreading usage, the most common complications included mesh erosion into the esophageal lumen sometimes even requiring distal esophagectomy[14,15], and others as esophageal stenosis or dense fibrosis[14], even mesh erosion into abdominal aorta resulting in massive hemorrhage[16]. Non-degradable characteristics of prosthetic mesh was the possible cause to these adverse effects, novel materials for mesh modification were applied as biologic mesh, it was reported that no mesh induced erosion was observed after use of human acellular dermal matrix patch [17], porcine dermal collagen matrix mesh[18], or porcine small intestinal submucosal patch $[13,19]$, whereas non-absorbable mesh tended to be associated with erosion and stricture[6]. Laparoscopic hiatal hernia repair with acellular human dermis reinforcement results in 
improvement of gastric reflux related symptoms and quality of life without mesh-associated complications [20-22].

\section{Conclusion}

High recurrence following EHH repair led to more popularity of mesh usage in order to decrease the high postoperative recurrence. Overall, use of prosthetic mesh reinforcement of cruroplasty in large hiatal hernias may prevent hernia recurrence effectively, but the severe mesh associated complications must be recognized and paid attention to clearly. The ideal mesh is considered being easy to handle and of perfect tolerance with human structure. Long-term follow-up and prospective randomized clinical trials are needed to investigate the safety and efficacy of mesh use for EHH repair. Novel materials such as biologic mesh for EHH repair may be promising.

\section{References}

1. Patti MG, Fisichella PM (2009) Laparoscopic paraesophageal hernia repair. How I do it. J Gastrointest Surg 13(9): 1728-1732.

2. Wijnhoven BP, Watson DI (2008) Laparoscopic repair of a giant hiatus hernia-how I do it. J Gastrointest Surg 12(8): 1459-1464.

3. Schlottmann F, Strassle PD, Farrell TM, Patti MG (2017) Minimally Invasive Surgery Should Be the Standard of Care for Paraesophageal Hernia Repair. J Gastrointest Surg 21(5): 778-784.

4. Luketich JD, Nason KS, Christie NA, Pennathur A, Jobe BA, et al. (2010) Outcomes after a decade of laparoscopic giant paraesophageal hernia repair. J Thorac Cardiovasc Surg 139(2): 395-404.

5. DeMeester SR (2013) Laparoscopic paraesophageal hernia repair: critical steps and adjunct techniques to minimize recurrence. Surg Laparosc Endosc Percutan Tech 23(5): 429-435.

6. Frantzides CT, Carlson MA, Loizides S, Papafili A, Luu M, et al. (2010) Hiatal hernia repair with mesh: a survey of SAGES members. Surg Endosc 24(5): 1017-1024.

7. Granderath FA (2017) Operative treatment of hiatus hernia: Evidence on mesh inlay. Chirurg 88(3): 211-218.

8. Champion JK, Rock D (2003) Laparoscopic mesh cruroplasty for large paraesophageal hernias. Surg Endosc 17(4): 551-553.

9. Granderath FA, Carlson MA, Champion JK, Szold A, Basso N (2006) Prosthetic closure of the esophageal hiatus in large hiatal hernia repair and laparoscopic antireflux surgery. Surg Endosc 20(3): 367-379.

10. Frantzides CT, Madan AK, Carlson MA, Stavropoulos GP (2002) A prospective, randomized trial of laparoscopic polytetrafluoroethylene
(PTFE) patch repair vs simple cruroplasty for large hiatal hernia. Arch Surg 137(6): 649-652.

11. Furnee E, Hazebroek E (2013) Mesh in laparoscopic large hiatal hernia repair: a systematic review of the literature. Surg Endosc 27(11): 39984008.

12. Huddy JR, Markar SR, Ni MZ, Morino M, Targarona EM (2016) Laparoscopic repair of hiatus hernia: Does mesh type influence outcome? A meta-analysis and European survey study. Surg Endosc 30(12): 5209-5221.

13. Oelschlager BK, Pellegrini CA, Hunter J, Soper N, Brunt M (2006) Biologic prosthesis reduces recurrence after laparoscopic paraesophageal hernia repair: a multicenter, prospective, randomized trial. Ann Surg 244(4): 481-490.

14. Stadlhuber RJ, Sherif AE, Mittal SK, Fitzgibbons RJ, Michael Brunt L (2009) Mesh complications after prosthetic reinforcement of hiatal closure: a 28-case series. Surg Endosc 23(6): 1219-1226.

15. Perez Lara FJ, Fernandez JD, Quecedo TG, Lafuente FC, Munoz HO (2014) Mesh extrusion into the esophageal lumen after surgery for a giant hiatal hernia. Am Surg 80(12): E364-E366.

16.Zugel N, Lang RA, Kox M, Huttl TP (2009)Severe complication of laparoscopic mesh hiatoplasty for paraesophageal hernia. Surg Endosc 23(11): 2563-2567.

17. Ringley CD, Bochkarev V, Ahmed SI, Vitamvas ML, Oleynikov D (2006) Laparoscopic hiatal hernia repair with human acellular dermal matrix patch: our initial experience. Am J Surg 192(6): 767-772.

18. Antoniou SA, Pointner R, Granderath FA (2011) Hiatal hernia repair with the use of biologic meshes: a literature review. Surg Laparosc Endosc Percutan Tech 21(1): 1-9.

19. Bettolli M, Rubin SZ, Gutauskas A (2008) Large paraesophageal hernias in children. Early experience with laparoscopic repair. Eur J Pediatr Surg 18(2): 72-74.

20. Ward KC, Costello KP, Baalman S, Pierce RA, Deeken CR (2015) Effect of acellular human dermis buttress on laparoscopic hiatal hernia repair. Surg Endosc 29(8): 2291-2297.

21. Puri V, Kakarlapudi GV, Awad ZT, Filipi CJ (2004) Hiatal hernia recurrence: 2004. Hernia 8(4): 311-317.

22. Asti E, Sironi A, Bonitta G, Lovece A, Milito P, et al. (2017) Crura augmentation with Bio-A((R)) mesh for laparoscopic repair of hiatal hernia: single-institution experience with 100 consecutive patients. Hernia 21(4): 623-628.
This work is licensed under Creative Commons Attribution 4.0 License

Submission Link: https://biomedres.us/submit-manuscript.php

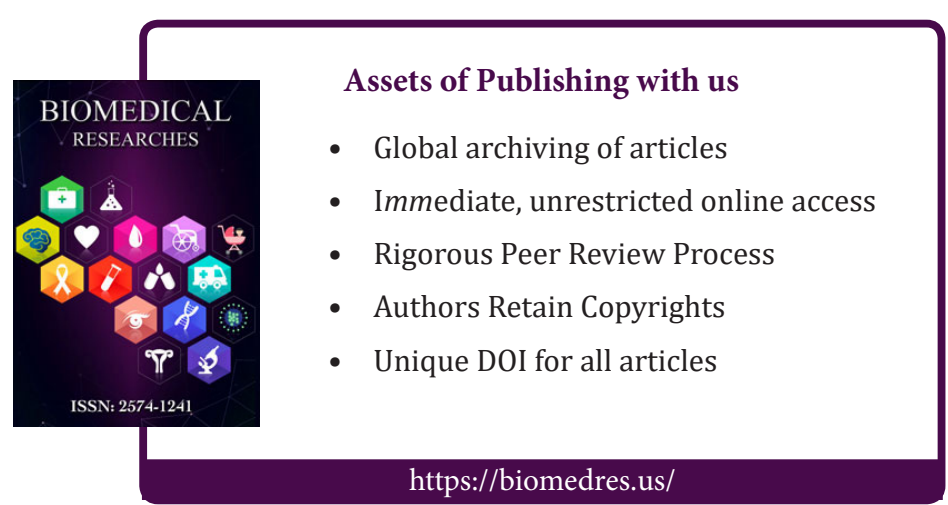

